\title{
Why Is It So Difficult to Optimally Choose Innovation? Lest We Forget the Real World
}

\author{
Partha Gangopadhyay ${ }^{1}$, Takemi Fujikawa $^{2} \&$ Yohei Kobayashi $^{3}$ \\ ${ }^{1}$ School of Economics and Finance, University of Western Sydney, Sydney, Australia \\ ${ }^{2}$ Faculty of Economics, Otemon Gakuin University, Ibaraki, Japan and Graduate School of Business, Universiti \\ Sains Malaysia, Penang, Malaysia \\ ${ }^{3}$ Brain Functions Laboratory, Yokohama, Japan \\ Correspondence: Partha Gangopadhyay, School of Economics and Finance, University of Western Sydney, \\ Locked Bag 1797, Penrith South DC, NSW 2751, Australia. Tel: 61-2-9685-9347. E-mail: \\ P.Gangopadhyay@uws.edu.au
}

Received: October 8, 2012

doi:10.5539/mas.v7n5p39
Accepted: April 5, $2013 \quad$ Online Published: April 19, 2013

URL: http://dx.doi.org/10.5539/mas.v7n5p39

\begin{abstract}
In order highlight the non-steady state and real world dynamics associated with competitive innovation we develop a model involving choice of product quality in a simple duopoly characterised by two key departures from the dominant framework of quality ladder: first, we consider firms who refrain from maximising short-run profits. Instead, firms are started their function or action by their long-run goal of survival and growth. Secondly, we introduce the full-cost pricing model as opposed to market clearing prices. Based on these two key features we are able to derive the dynamics that can characterise the evolution of product quality in the non-steady state. We establish that the presence of an unstable equilibrium creates a threshold effect, which can also give rise to either a virtuous or vicious, path of quality choices. We further show that the quality dynamics can exhibit chaotic behaviour. As a consequence, firms become unsuccessful to see systematic errors. Firms also become unsuccessful to make long-run predictions with certainty even though they act in a deterministic world. The corollary is that time profiles will separate exponentially and these time profiles begin very close together. We offer interesting simulations to support the theoretical findings.
\end{abstract}

Keywords: regions of instability, full-cost pricing models, Chaotic dynamics

\section{Introduction}

High-tech products have, in recent years, assumed paramount significance in the prosperity of nations. These products seriously impinge on the quality of life for millions. Autos, health merchandise, the internet and PCs are among a wide array of products that have long gone high-tech. The quality of these products is ever-changing as new products regularly replace old products. The quality of a product also poses serious challenges to a firm as its long-run survival and growth are intrinsically predicated on its ability to compete with rivals in quality.

We examine the quality competition in a novel framework: in our framework a typical firm is assumed to be a duopolist (can be easily extended to an oligopolist) with a particular internal structure and group of investment necessities that are hinged upon their long-run goals of survival and growth (Arestis \& Milberg, 1994). Our proto-type firm is therefore different from the postulated firms of the steady state framework of quality choice that assumes firms to be solely driven by their short-term goals of profit-maximization along the steady state path. In the existing literature the standard model of innovation assumes that the product development, or progress, takes place along a pre-existing quality ladder. An innovator is actuated by ex ante excess, or monopoly, profits that the innovator expects to acquire at each rung of the quality ladder. There is a fixed cost of innovation and an innovator, hence, jumps from one rung to the next only when the ex ante excess profits can outweigh the exogenous fixed costs. For more than seven decades, since it was first advanced in Schumpeter (1942), the standard model has been the primary tool in order to explain the dependence of technology progresses on economic fundamentals such as patience and cost (Boldrin \& Levin, 2009). This model of innovation has been used as the propelling force behind economic growth in the models of Romer (1990), Grossman and Helpman (1991), and Aghion and Howitt (1992), among other. The important issue of technological diffusion across space 
has been examined in Hopenhayn (2006) by using this primary tool of competitive innovation in the context of the quality ladder.

A recent innovation in the research on innovation has addressed the question of opportune timing of innovation as undertaken by Boldrin and Levin (2008): they develop a theory of competitive innovation in which we introduce new ideas only when diminishing returns to the use of existing ones are happened. Once a new idea is introduced, the knowledge capital associated with such a new idea expands, and its value falls. Once the value falls far enough, it becomes profitable for firms to introduce a new idea to cover the fixed cost of adopting the new idea. Both the traditional Schumpeterian theory of innovation and the subsequent developments by Boldrin and Levin $(2008,2009)$ are rooted in the steady state of the postulated dynamics of innovation. In the existing framework the optimal innovation is given by the equality of the net return from innovation to the subjective interest rate of an innovator. The main drawback of the steady state analysis of the quality ladder is that there is a paltry attention accorded to the question of whether agents can come to share the steady state expectations. In other words, the convergence on the ex ante steady state is given a short shrift.

The relevant question for us is whether agents are capable of reaching the steady state. The main contribution of the current paper is to develop a model to understand the dynamics of innovation by agents and to examine whether agents can reach the steady state from an arbitrary starting point. The main problem with the dominant strand of research on innovation is its sole reliance on the steady state equilibrium analysis as a tool of investigation. However research and development, and product innovation continually alter product quality. Product innovation thus embraces a very dynamic field that is, in turn, influenced by bubbles of expectations, desires for market domination and a constant quest for survival. It thus seems that the equilibrium approach to modelling product quality ignores various important facets of this arena of research.

One may like to argue that the steady state analysis is a general weakness of the modern industrial economics. In other words, industrial economists typically draw their attention on economic models with regions of local stability on the assumption that the regions of instability are of little significance but rather more of a pathological case. The main justification for using the equilibrium analysis can pivot on the simple fulcrum that industrial economics does not address exploding time paths of any significant industrial variable. This justification is incorrect once one considers the possibility of introducing chaotic dynamics in the literature. The development of chaotic behavior significantly puts down the dismissal of regions of instability that can indeed generate complex, but deterministic, dynamics within bounds. In order to understand the quality competition we consider the full-cost pricing models as developed by Kalecki $(1954,1971)$, Steindl (1952) and Weintraub (1959). From the non-maximizing behaviour of a firm and the full-cost pricing models we are able to develop a dynamic model that offers interesting findings in the context of quality competition.

We highlight the importance of chaotic behavior in the context of industrial economics as already highlighted in early work of Furth (1986), Kopel (1996) and Puu (1998). The major innovation of our paper is three-fold: first, we consider the race for market domination via product quality between rivals who seek long-run survival and growth-instead of short-run profits. Secondly, we develop a simple model to capture the dynamics and fluidity associated with innovation and product quality from a simple model of full-cost pricing. Finally, we strain the theory of chaos to shed lights on the time profile of product quality. Simulations are undertaken to provide support to our theoretical findings. The plan of the paper is as follows: Section 2 offers a brief literature review and Section 3 develops the model and Section 4 provides a discussion of the findings. Section 5 document simulation results and Section 6 concludes.

\section{Related Lieterature on Quality Choice}

There is no gainsaying to the fact that a lot of research on quality has already taken place in the static neoclassical framework. Unfortunately, the research has also created some confusion, possibly due to its reliance on an incorrect modelling framework for the problem associated with quality competition. Papers by Gabszewicz and Thisse (1979, 1980) and Shaked and Sutton (1982) developed models that indicate what levels of qualities to exist in an industry and the number of different quality brands which are produced in an industry with free entry and exit. It has also shown whether there is existence of any causal relationship between the degree of monopoly power of a firm and its choice of product quality (Schmalensee, 1979). Early works by Kleiman and Ophir (1966) and Levhari and Srinivasan (1969) argued that when firms have monopoly power they have incentives to produce goods with lower qualities. However, Swan $(1970,1971)$ established the counter-intuitive result that there is no causal relationship between monopoly power and quality. A number of papers have been triggered by the Swan's independence result in analysing the independence result (Kihlstrom \& Levhari, 1977). Here are two notions: (1) A product quality is not often readily recognised by consumers and (2) Producers typically have more information about their product 
qualities. In light of these two notions, a number of papers pay their attention to the problem of asymmetric information and signalling issues (Wolinsky, 1983). Within the neoclassical framework, it is hence very unclear how product qualities evolve over time.

The explicit modelling of quality variation in markets characterised by asymmetric information, which causes market thinness, was initiated in the classic paper by Akerlof (1970). The classic lemons model is static. The distribution of quality and hence the average level of quality is exogenously determined in the model, which is not a good representative of modern markets where sellers can choose and commit to the level of quality of their product and will change their choices over time as the market evolves. Furthermore, the Akerlof's results are substantively different even though one allows for endogenous quality choice, which is expected to generate a unique and stable equilibrium as in Hopenhayn (1992). The reason for this is that costly investment becomes attractive even if one-shot gains are lower due to the future expected payoffs. In contrast our model does not use a perfect foresight hypothesis of Hopenhayn (1992) and allows firms to adopt a "groping" strategy, instead of an instantaneous (intertemporal) optimization strategy, for choosing quality and altering quality choices over time.

Our model of quality choice has predecessors in the form of endogenous quality choice that is shown in the Industrial Organization (IO) literature (Shapiro, 1983, for example). These models usually use account to sustain equilibria involving investment in quality that involve one period losses. In other words, these models rely on the long-term optimization by firms in the choice of quality while firms are endowed with perfect foresight: in contrast, our firms choose quality not in the static optimization framework. We rather analyse an environment where quality can evolve through time, yet there may not arise a steady state to the dynamic path of evolution. It is important to note that there is a serious weakness that the IO models have: demand is not endogenous in these reputation models because of which one can get a unique outcome in the models. With endogenous demand, one can show that the uniqueness result no longer holds. It is true that multiple equilibria models are no longer new in economics literature, but the multiplicity of equilibrium can create serious problems for equilibrium selection. In the static version of our model also, one can derive a special case of multiple equilibria, which is however not the concern in the current paper since the focus of ours is overtly dynamic.

For obtaining a case of multiple equilibria in the context of product quality, one can introduce some of the enduring features of most multiple equilibria models, in particular, exhibiting strategic complementarities (Cooper \& John, 1988; Cooper, 1999). However, all of these models are usually static in nature and have an increasing returns property inbuilt either in the matching technology (Diamond, 1982) or in players' payoff functions. In other words, these pure coordination models represent one-shot games in which current actions are not determined by future expectations.

In contrast, our model does not have an increasing returns property and our model introduces an expectational operator to drive the evolution of quality. In its focus on multiplicity of equilibrium for explaining underdevelopment, this also relates to the work of Murphy, Shleifer and Vishny (1989). However, authors do not introduce the intertemporal context of firm behaviour, nor can they be used to analyse the interaction of the supply of high quality goods and its demand. Many of previous literature suggested that calculations about the future and comparison of current gains with future losses should be made a part of a typical firm's optimising behaviour-in other words one should externally choose the value attached by different firms to current payoffs as against future payoffs. It is an interesting idea but we do not attempt to understand the time profile of quality choices when firms have different discount rates for future profits. Instead, in this paper, we explicitly model the quality dynamics from the adjustment behaviour of decision-makers without any explicit consideration of discount rates. In the simulation we also demonstrate how the quality dynamics evolves over time.

The money literature has presented endogenous quality models as well. The previous authors purpose is, however, to examine how money acts as a uniform quality good and its effect in reducing uncertainty on quality and therefore on the supply of high quality goods and welfare (Williamson \& Wright, 1994; Bernsten \& Rocheteau, 2004). Once again, the focus of this literature is a purely static equilibrium and we know little about the evolution of a single currency as a uniform quality good. Our model can be extended to explain the evolution of rival currencies and their exchange rates and their fluctuations, which is not the concern of the current paper.

For a to some extent different type of model focusing on coordination failure leads to suboptimal equilibria (Basu, 1986). His model asserts that different conjectures lead to different equilibria, showing how expectations crucially determine the equilibrium. In contrast our model posits a single conjectural function and shows how a complex behaviour can evolve from the proposed model. This interlinkage of choices across time has been captured with a different view by Ghosh and Ray (1996) where buyers repeatedly make entry into the market and, thus, market history matters. However their work deals with the levels of cooperation that can be sustained 
when bad past conduct of sellers cannot be penalised. Kranton (1996) presented another related work: It shows how a rise in market thickness can cause alternate forms of exchange (like reciprocal exchange as a form of cooperation) to diminish, while the extensive use of personalised exchange can itself make markets remain thin, thus making such exchanges persist over time. In contrast to these papers, our paper focuses solely on rivalry and not on cooperation among firms in their choice of product quality. There is an extensive literature that looks at sustaining cooperation when there exist no official law enforcement agencies (Tirole, 1996) who mentioned a scenario in which only one party has an incentive to cheat and Dixit (2003) in which both parties can cheat). The role of intermediaries (though not discussed formally in this paper) is an important complementary aspect of research, to which our model can add new dimensions. Two papers are highlighted here that examine the role of intermediaries: Liebi (2002) and Quesada and Peyrache (2004). In our future work we have an intention to apply the non-neoclassical framework to the issues concerning evolution of cooperation and intermediaries in the context of choice of quality.

\section{Developing a New Model of Quality Competition}

We consider the simplest form of an oligopoly: a market where there exist duopolists (hereafter sellers) selling a good to a large number of consumers. We assume consumers' disposable income is constant and given as Y. It is postulated that a fraction $(\alpha)$ of income $Y$ is spent on this good in question. Thus, the total expenditure on this good is $\alpha \mathrm{Y}$. We do not derive the demand function from any underlying utility maximisation exercises. Both sellers sell their goods at the same point in time. We assume that a fraction $h_{i}$ of $\alpha Y$ is spent on the good sold by seller $i$. The rivalry between these two sellers is introduced by this coefficient $h_{\mathrm{i}}$. We postulate that the higher the relative quality of this product sold by seller $i$, the higher is the value of $h_{i}$, which represents a larger share of the market for seller $i$. We assume that the quality of a product can be characterised by a variable $\Pi$ and the higher the quality the higher the value of $\Pi$. Each seller therefore has an incentive to out-compete one's rival in quality to enhance one's market shares and survival. We represent these ideas in the following notations:

Output sold by seller is $\mathrm{Q}_{\mathrm{i}}$ :

$$
Q_{i}=\alpha Y h_{i} \text { while } i \forall 1,2
$$

We assume a simple linear relationship between $h_{\mathrm{i}}$ and $\Pi_{\mathrm{i}}$ and $\Pi_{\mathrm{j}}$ :

$$
h_{i}=h_{0}+\gamma\left(\Pi_{i}-\Pi_{j}\right)
$$

Equation (1b) states that the sales of seller are positively related to the quality advantage of seller $i$.

We assume the unit cost of production $\left(\mathrm{C}_{\mathrm{i}}\right)$ of seller $\mathrm{i}$ to be linear in quality variable $\Pi_{\mathrm{i}}$ :

$$
C_{i}=\beta_{0}+\beta_{1} \Pi_{i}
$$

We assume a simple mark-up pricing rule so that the price of good sold by seller i $\left(\mathrm{P}_{\mathrm{i}}\right)$ is given by

$$
P_{i}=M_{i} C_{i}=M_{i}\left(\beta_{0}+\beta_{1} \Pi_{1}\right) \text { where } M_{i}>1
$$

This is a simple version of Kaleckian full-cost pricing as Kalecki (1971) has shown how pricing in the manufacturing sector depends on 'the degree of monopoly of the firm's position. The degree of monopoly depends on a set of environmental and institutional factors (Reynolds, 1987). We however ignore the effect of average price of rivals on the price charged by a seller. The profits of seller $i$ is $R_{i}$ that is given as

$$
R_{i}=\alpha Y\left(M_{i}-1\right)\left[\left(\beta_{0}+\beta_{1} h_{0}\right) \Pi_{i}+\beta_{1} \Pi_{i}^{2}-\left(\beta_{0}+\beta_{1} \Pi_{i}\right) \Pi_{j}+\beta_{0} h_{0}\right]
$$

A typical neoclassical model now performs maximization of (2a) with respect to $\Pi_{\mathrm{i}}$ that will give the following best response rule of seller i in terms of his product quality $\Pi_{\mathrm{i}}$ :

$$
\begin{aligned}
\Pi_{i} & =A_{1}+E\left(\Pi_{j}\right) / 2 \\
A_{1} & =-\frac{\left(\beta_{0}+\beta_{1} h_{0}\right)}{2 \beta_{1}}
\end{aligned}
$$

where $E\left(\Pi_{j}\right)$ is the expectation of seller $i$ of the quality of product sold (simultaneously) by seller $\mathrm{j}$. We do not any restriction on the values of $\Pi_{i}$, it can be positive or negative or zero. What we are interested is the divergence between $\Pi_{\mathrm{i}}$ and $\Pi_{\mathrm{j}}$ as the driver of quality dynamics. In order to make it economically meaningful, one may like to consider the variable $\Pi_{\mathrm{i}}$ as a deviation from some standard, norm, quality. The negative (positive) value implies a chosen quality less (more) than the standard, or norm.

The deductive equilibrium approach imposes a condition here regarding the expectation of seller $i$ as typified in the Cournot-Nash equilibrium (Gangopadhyay, 2000), or in rational expectations models (Gangopadhyay, 1999): the 
assumption is known as zero conjectural variation that posits that seller $\mathrm{i}$ assumes that seller $\mathrm{j}$ will keep the strategic variable constant as he varies his strategic variable (in our case quality). Then a mutual consistency assumption is introduced to home in on the Cournot-Nash, or rational expectations, equilibrium (Gangopadhyay, 2005). It is well recognised that the true dynamics has been ditched at this point of investigation. In order to introduce non-equilibrium dynamics and characterise the quality dynamics we introduce the following key assumptions:

Assumption 1: Each seller refrains from maximising short-run profits and, instead, focuses on its survival and growth by the choice of quality in an incremental fashion. At date $t+1$ seller adjusts quality $\Pi_{I}(t+1)$ by the following rule:

$$
\Pi_{i}(t+1)=\Pi_{i}(t)+a\left[\frac{\partial R_{i}(t)}{\partial \Pi_{i}(t)}\right]
$$

where $\left[\partial \mathrm{R}_{\mathrm{i}}(\mathrm{t}) / \partial \Pi_{\mathrm{i}}(\mathrm{t})\right]$ is the partial derivative of the profit function with respect to own quality, 'a' is the adjustment coefficient.

Equation (2b') states that if quality adjustment raises (lowers) profits at date $t$ by one dollar, then the seller augments (lowers) the quality by this coefficient 'a'. Substituting the relevant equations yields

$$
\Pi_{i}(t+1)=a \beta_{0}+a \beta_{1} h_{0}+\left(1+2 a \beta_{1}\right) \Pi_{i}(t)-a \beta_{1} E\left[\Pi_{j}(t+1)\right]
$$

where $E\left(\Pi_{j}(t+1)\right)$ is seller $i$ 's expectation of the quality to be chosen by seller $j$ at date $(t+1)$.

Assumption 2: We assume $\mathrm{E}\left(\Pi_{\mathrm{j}}(\mathrm{t}+1)\right)$ be given by the following:

$$
E\left[\Pi_{j}(t+1)\right]=F\left[\Pi_{i}(t)\right]=N_{1} \Pi_{i}(t)-N_{2}\left[\Pi_{i}(t)\right]^{2}+N_{3}
$$

We assume the same for seller $\mathrm{j}$.

First, it is important to note that the assumption (3a) is a breach of the deductive equilibrium approach - since we have not introduced the syntactic concept of equilibrium here (Gangopadhyay, 2004a, b). Secondly, the assumption of (3a) posits a shared mental process: each seller thinks that as he chooses a higher quality to dominate the market (as seen by market shares) his rival will oppose this tactic by choosing a higher quality till a point $\left(\mathrm{N}_{1} / 2 \mathrm{~N}_{2}\right)$. Beyond this threshold each seller thinks that the rival will acquiesce to his dominance by scaling down the quality. This assumption subsumes some kind of an anticipated conflict as reflected in the increases in quality of each product when both sellers attempt to dominate the market. As the conflict reaches the threshold each expects the other to roll over.

As opposed to Assumption 2, the deductive equilibrium approach assumes that each seller thinks that the rival will not change its quality (strategic variable) if he changes his quality to dominate the market. What it boils down to is an implicit assumption made by the deductive equilibrium approach that each seller assumes there will be no market conflict as the rival is always going to capitulate by not responding to his tactics to dominate the market. This assumption may be realistic in some cases, but it seems completely naïve to believe that this assumption carries much weight when sellers aggressively compete against each other in developing new products and improving product quality to enhance their market shares for survival and growth. From the above we offer the following results.

Result 1: The dynamics governing the quality of product of seller is reduced to the following:

$$
\Pi_{i}(t+1)=\gamma_{3}+\gamma_{2} \Pi_{i}(t)^{2}+\gamma_{1} \Pi_{i}(t)
$$

where $\gamma_{3}=a \beta_{0}+a \beta_{1} h_{0}-a \beta_{1} N_{3}, \gamma_{2}=a \beta_{1} N_{2}, \gamma_{1}=1+2 a \beta_{1}-a \beta_{1} N_{1}$.

Proof: Substituting (3a) into (2b') yields (4a). QED.

Assumption 3: We make a simplifying assumption to make the analysis tractable:

$$
\Pi_{i}(t)=\Pi_{j}(t)=\Pi(t)
$$

Assumption 3 makes the analysis much easier without losing much analytical bite. It is also important to note that equation (4b) can only yield one fixed point (steady state) from equations (1a) and (1b). By so doing, we explicitly side-step interesting cases of multiple equilibria, which can further complicate the dynamics of choice of quality. But, from Feigenbaum (1978) and May (1976), even from a unique fixed point, or steady state of the dynamic path, we know that the second iterates cause more fixed points and the stability of the system has to be considered in the light of Equations (4a) and (4b).

Result 2: The dynamics of product quality as described in (4a) and (4b) has in fact two fixed points, or steady 
states,

$$
\begin{aligned}
& \Pi^{*}=\frac{1-\gamma_{1}}{2 \gamma_{2}}-\frac{\sqrt{\left(1-\gamma_{1}\right)^{2}-4 \gamma_{2} \gamma_{3}}}{2 \gamma_{2}} \\
& \Pi^{* *}=\frac{1-\gamma_{1}}{2 \gamma_{2}}+\frac{\sqrt{\left(1-\gamma_{1}\right)^{2}-4 \gamma_{2} \gamma_{3}}}{2 \gamma_{2}}
\end{aligned}
$$

The stability of fixed points requires:

$$
\Pi<\frac{1-\gamma_{1}}{2 \gamma_{2}}
$$

Thus, $\Pi^{*}$ is a stable fixed point under a restriction while $\Pi^{* *}$ is an unstable fixed point. Thus, in the old literature such models are believed to have a unique attractor $\Pi^{*}$. QED.

Result 3: The first fixed point $\Pi^{*}$ loses stability if

$$
\sqrt{\left(1-\gamma_{1}\right)^{2}-4 \gamma_{2} \gamma_{3}}=2
$$

The first fixed point $\Pi^{*}$ is stable if

$$
\sqrt{\left(1-\gamma_{1}\right)^{2}-4 \gamma_{2} \gamma_{3}}<2
$$

Proof: Simple substitutions yield the results. QED.

Now it is possible to derive two limits on $\Pi$ within which the quality is to be bounded. We call them $\Pi^{\mathrm{MIN}}$ and $\Pi^{\mathrm{MAX}}$ and note

Note that the quality dynamics is bounded if

$$
\begin{aligned}
& \Pi^{M I N}=\Pi^{* *}-\frac{\gamma_{1}}{\gamma_{2}} \\
& \Pi^{M A X}=\Pi^{* * *}
\end{aligned}
$$

$$
\begin{gathered}
\Pi(t)<\Pi^{M A X}=\Pi^{* *} \text { for } t=0,1,2, \ldots \\
\Pi(t)>\Pi^{M I N}=\Pi^{* *}-\frac{\gamma_{1}}{\gamma_{2}} \text { for } t=0,1,2, \ldots \\
\sqrt{\left(1-\gamma_{1}\right)^{2}-4 \gamma_{2} \gamma_{3}}<3
\end{gathered}
$$

It is possible to make suitable changes in variables to obtain the following dynamics:

$$
\begin{gathered}
X_{t+1}=A X_{t}\left(1-X_{t}\right) \\
A=\sqrt{\left(1-\gamma_{1}\right)^{2}-4 \gamma_{2} \gamma_{3}}+1 \\
X_{t}=\frac{\gamma_{3}\left[\Pi^{* *}-\Pi(t)\right]}{A}
\end{gathered}
$$

Observation 1: The quality dynamics converges to the stable fixed point $\Pi^{*}$ if $1<A<3$. However, the fixed point $\Pi^{*}$ becomes unstable if $\mathrm{A}>3$ and a two-period quality cycle appears. If $\mathrm{A}>3.57$ the quality cycle evolves through a cycle of infinite time period. The quality is bounded within the aforementioned limits (7a) and (7b), yet the quality never repeats itself (May, 1976). 


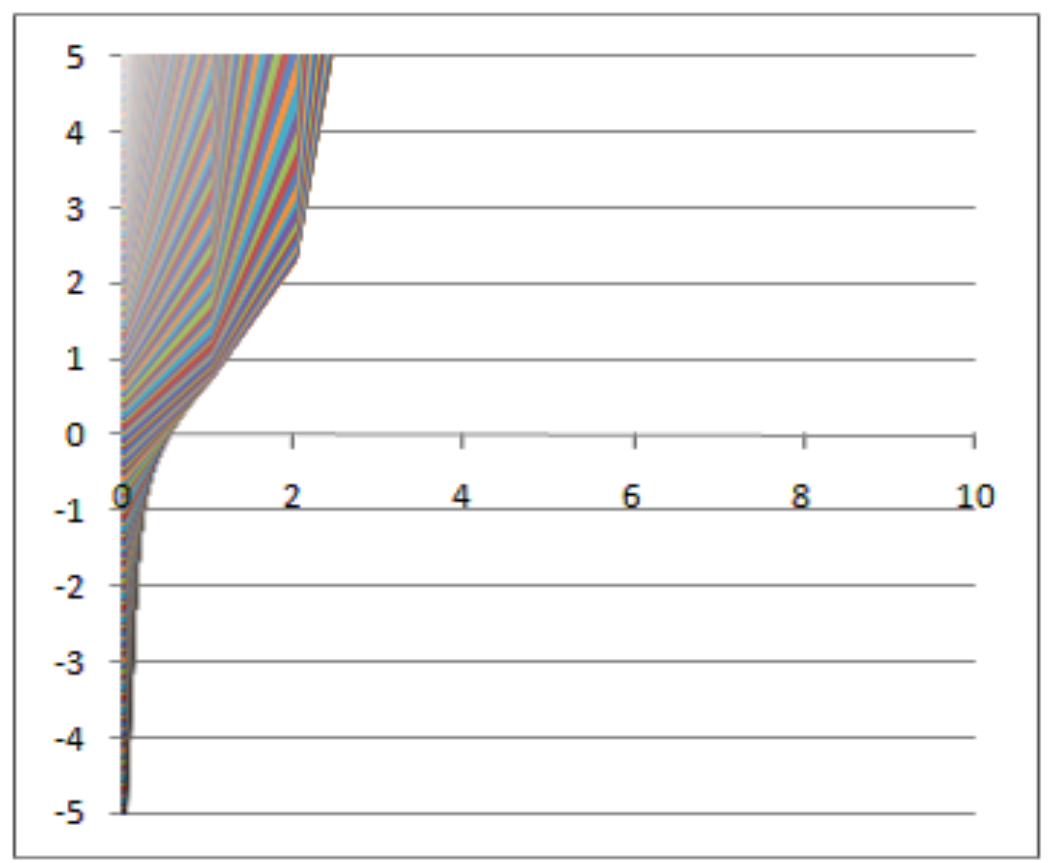

Figure 1. $\mathrm{g}_{1}=1, \mathrm{~g}_{2}=1, \mathrm{~g}_{3}=1$

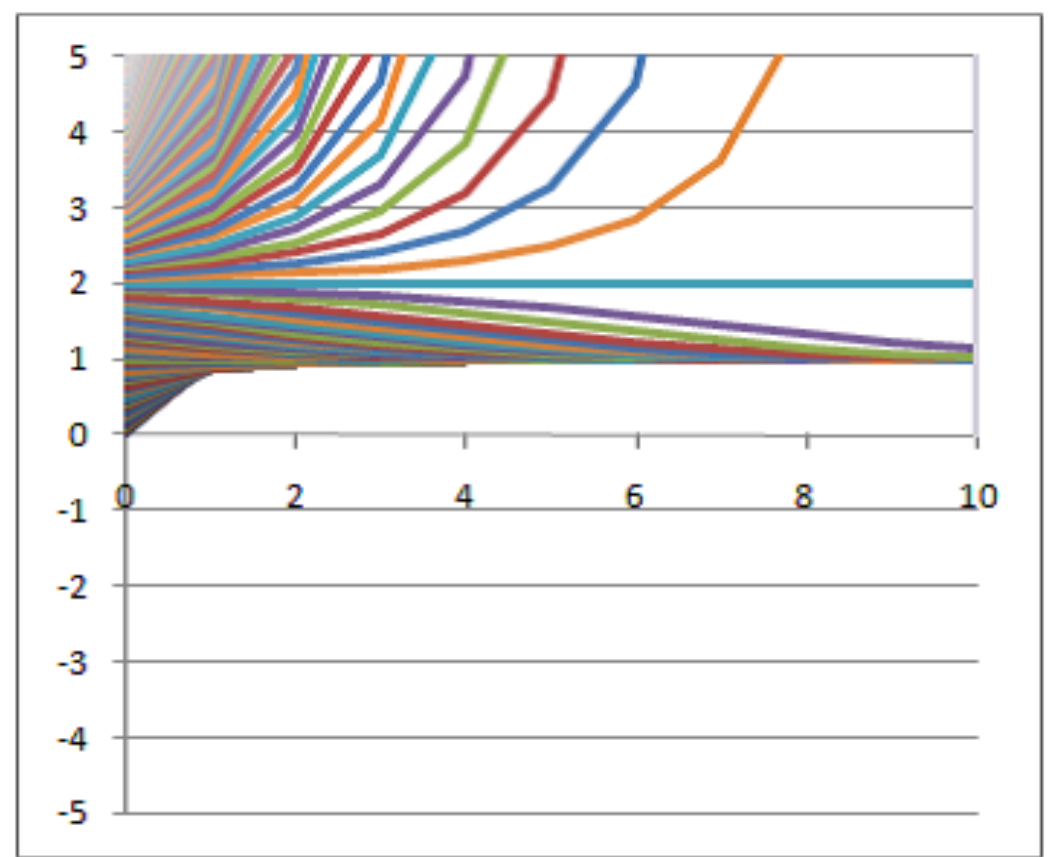

Figure 2. $\mathrm{g}_{1}=0.5, \mathrm{~g}_{2}=-0.5, \mathrm{~g}_{3}=1$

\section{Discussion of Primary Results}

We can now characterise the dynamics: for $1<\mathrm{A}<3$ the dynamics of product quality will converge to the stable steady state. This region of stability serves an important role in equilibrium analysis as discussed in Gangopadhyay (2005) and Gangopadhyay (1997). If A is increased beyond 3, $\Pi^{*}$ becomes unstable and the quality competition converges to a stable 2-period cycle. As A is further increased the stable n-period cycles bifurcates into 2n-period cycles. We know from Feigenbaum (1978) that the range of A for which the nth cycle is stable shrinks at a geometric rate. For $\mathrm{A}>3.57$ the quality dynamic evolves through an infinite period cycle. The quality choices are within the relevant bounds, however never repeated. For a higher order quality choices may seem a random process however these choices are fully deterministic. 


\section{Simulations}

From (4a) and (4b), we are able to calculate the temporal development of $\Pi_{i}(t)$ from various assumed initial values and check their stability for different values of parameters. We calculate the temporal development, from the initial value chosen from $\Pi_{i}(0)=-5$ to $\Pi_{i}(0)=5$. The relevance of negative values for $\Pi_{\mathrm{i}}$ is explained on pp. 8 in the paragraph after equations (2b) and (2c). By construction of the model, we can obtain four typical patterns as Figure 1 to Figure 4. Figure 1 type has no fixed point and every $\Pi_{i}(t)$ increases forever.

Figure 2 type has two fixed point and stable fixed point is lower than unstable one. Figure 2 thus presents the standard model innovation traditionally highlights a unique equilibrium as the attractor of any time profile of choice variables as long as the initial quality and expectations are less than the value of the unstable fixed point. Contrary to the import of these existing models, our finding is that the possibility of an unstable fixed point being greater than the stable one will keep the possibility of a virtuous path of growth in quality that can result in an "explosion in quality".

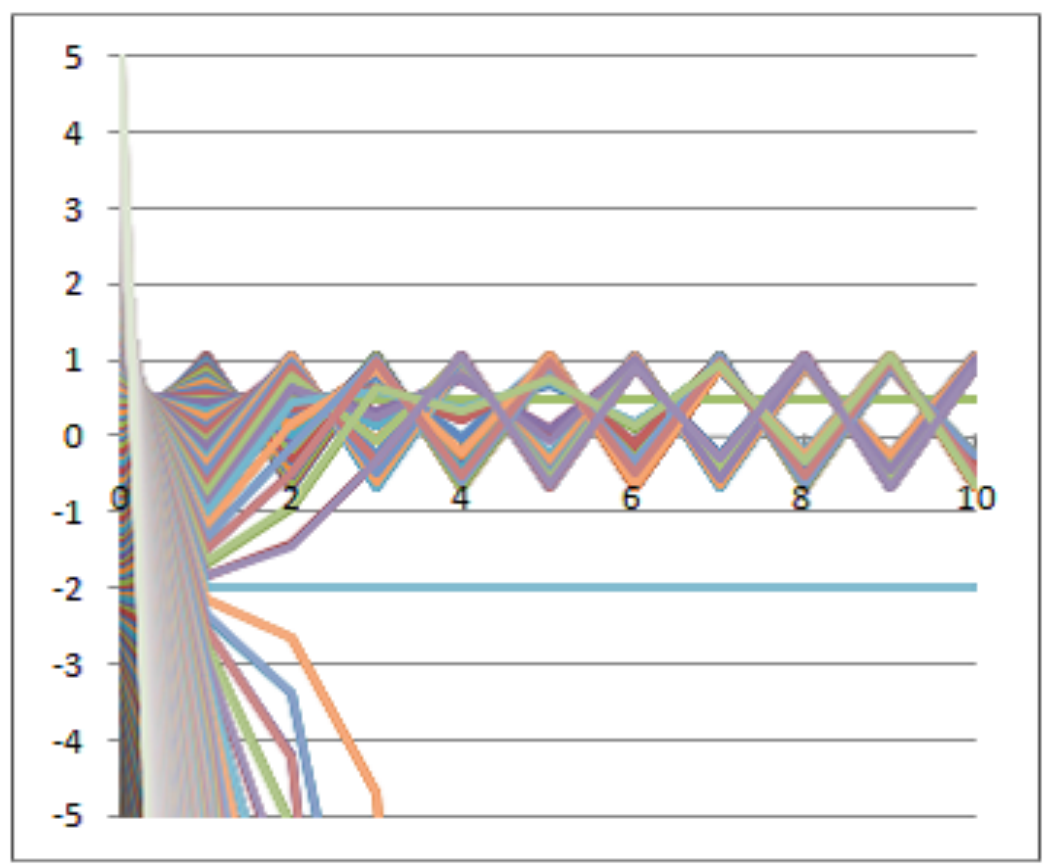

Figure 3. $\mathrm{g}_{1}=-0.5, \mathrm{~g}_{2}=-1, \mathrm{~g}_{3}=1$

Figure 3 type also has two static fixed points and the stable fixed point is higher than the unstable one. The unstable fixed point acts as a separatrix. In order to achieve the stable equilibrium, the system must ensure that either the initial quality, or expectations about it, must exceed the threshold value given by the unstable fixed point. Otherwise, the dynamic path of quality will drive the system along the vicious path of decline in quality. Our model hence can explain fluctuations in quality in different systems, especially why quality steadily improves in some setup while quality simultaneously, and secularly, declines in others. It also helps understand why some economic and political systems find it arduous to achieve a significant progress in quality of various social, institutional economic variables. Also this figure shows that, around the stable static point, $\Pi_{i}(t)$ value vibrates over the fixed point steadily.

Figure 4 type has two unstable fixed points and every $\Pi_{i}(\mathrm{t})$ decrease finally. The high fixed point is stable if the system is continuous. However this is a discrete system, the stability failed by its intense dynamics. From the observation of these types, we are able to calculate which initial value $\Pi_{i}(0)$ range can reach the fixed point and estimate the stability of the system for each value. Figure 5 shows the range of $\Pi_{i}(0)$ for which the system can engender stable dynamics. If the value of $\Pi_{i}(0)$ is 0 , the system has no fixed point or only has unstable fixed point. If the initial value is larger than 0 there is an existence of the initial value $\Pi_{i}(0)$ that can lead to a stable fixed point after a while. 


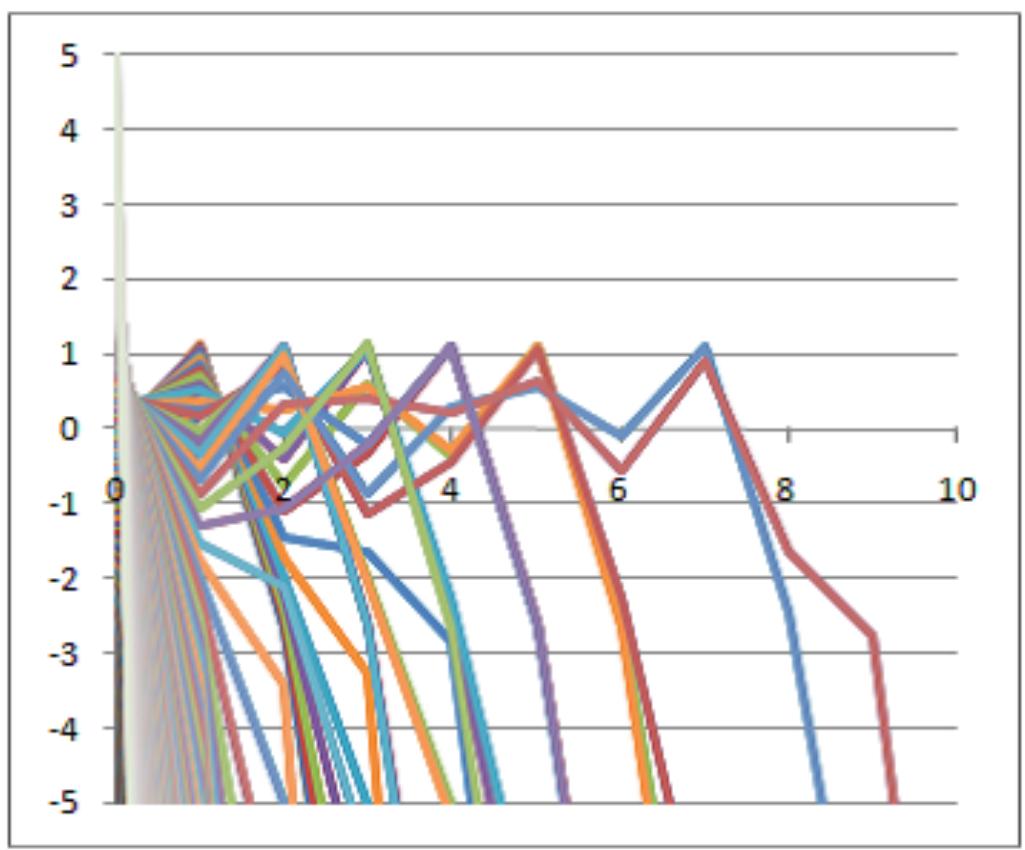

Figure 4. $\mathrm{g}_{1}=-1, \mathrm{~g}_{2}=-2, \mathrm{~g}_{3}=1$

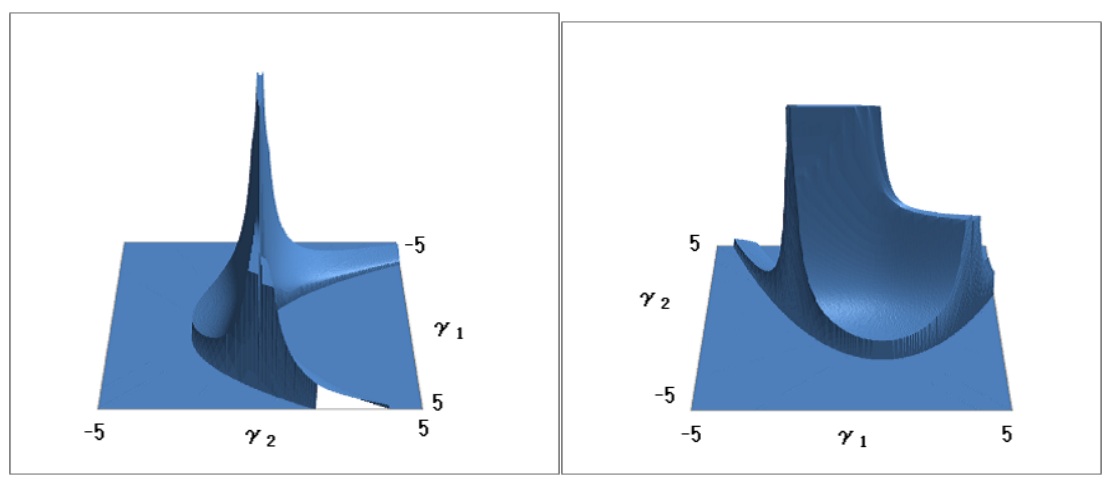

Figure 5. Stability properties for various values of $g_{1}$ and $g_{2}\left(g_{3}=1\right.$ fixed $)$

\section{Conclusion}

The finding has important implications: the deductive equilibrium approach to modern economic theory typically assume that all systematic prediction errors are dispelled by the Nash equilibrium, and the economic system settles in an equilibrium characterised by self-confirming and mutual-best responses. In this approach, there is most dominant influence on modern industrial economics, commonly known as industrial organization. The deductive equilibrium analysis may have contributed to the understanding of modern industrial economics. Little attention, however, has been paid to the regions of instability in the context of innovation.

Our model has important findings for situations in which decision-makers consciously choose quality of a product, or institution, to advance one's self-interest. In such a setup we explain two sets of results that can important implications for various economic, political and social systems: first and foremost, our model shows the importance of an unstable equilibrium that can give rise to either a virtuous growth path, or a vicious path of steady decline in quality. Our model also highlights the importance of a threshold effect to explain why a system tends to fail to achieve an efficient equilibrium of quality. Secondly, we establish that the postulated quality dynamics can generate chaotic behaviour. Firms fail to observe systematic errors. Firms also fail to produce long-run predictions with certainty even if they act in a deterministic world. Time profiles will separate exponentially and these profiles start very close together. We would like to conclude that an application of standard results of chaotic behaviour in the context of firms' competitive innovation can be promising in understanding of the dynamics of quality for any system in which quality matters. 


\section{References}

Aghion, P., \& Howitt, P. (1992). A model of growth through creative destruction. Econometrica, 60(2), 323-361. http://dx.doi.org/10.2307/2951599

Akerlof, G. (1970). The market for Lemons: Qualitative uncertainty and the market mechanism. Quarterly Journal of Economics, 84(3), 488-500. http://dx.doi.org/10.1017/CBO9780511609381.002

Arestis, P., \& Milberg, W. (1994). Degree of monopoly pricing, and flexible exchange rates. Journal of Post Keynesian Economics, 16(2), 167-188.

Banerjee, A. V., \& Newman, A. F. (1993). Occupational choice and the process of development. Journal of Political Economy, 101(2), 274-298. http://dx.doi.org/10.1086/261876

Basu, K. (1986). One kind of power. Oxford Economic Papers, 38(2), 259-282.

Berentsen, A., \& Rocheteau, G. (2004). Money and information. Review of Economic Studies, 71(4), 915-944. http://dx.doi.org/10.1111/0034-6527.00309

Boldrin, M., \& Levine, D. K. (2008). Against intellectual monopoly. Cambridge University Press.

Boldrin, M., \& Levine, D. K. (2009). A model of discovery. American Economic Review Papers and Proceedings, 99, 337-342. http://dx.doi.org/10.1257/aer.99.2.337

Cooper, R., \& John, A. (1988). Coordinating coordination failures in Keynesian models. Quarterly Journal of Economics, 103(3), 441-463. http://dx.doi.org/10.2307/1885539

Cooper, R. (1999). Coordination games complementarities and macroeconomics. Cambridge University Press. Diamond, P. (1982). Aggregate demand management in search equilibrium. Journal of Political Economy, 90(5), 881-894. http://dx.doi.org/10.1086/261099

Dixit, A. (2003). On modes of economic governance. Econometrica, 71(2), 449-482. http://dx.doi.org/10.1111/1468-0262.00415

Feigenbaum, M. J. (1978). Quantitative universality for a class of non-linear transformations. Journal of Statistical Physics, 19, 25-52. http://dx.doi.org/10.1007/BF01020332

Furth, D. (1986). Stability and instability in oligopoly. Journal of Economic Theory, 40(2), 197-228. http://dx.doi.org/10.1016/0022-0531(86)90072-4

Gabszewicz, J., \& Thisse, J. (1979). Price competition, quality and income disparities. Journal of Economic Theory, 20(3), 340-359. http://dx.doi.org/10.1016/0022-0531(79)90041-3

Gabszewicz, J., \& Thisse, J. (1980). Entry (and exit) in a differentiated industry. Journal of Economic Theory, 22(2), 327-338. http://dx.doi.org/10.1016/0022-0531(80)90046-0

Gangopadhyay, P. (1997). Differential profit rates and convergence to the natural state. Manchester School of Economic \& Social Studies, 65(5), 534-567. http://dx.doi.org/10.1111/1467-9957.00081

Gangopadhyay, P. (1999). On the feasibility of interest rate control: The role of disequilibrium and adaptive learning. Metroeconomica, 50(1), 87-117. http://dx.doi.org/10.1111/1467-999X.00064

Gangopadhyay, P. (2000). On the Coase theorem and coalitional stability: The principle of equal relative concession. Theory and Decision, 48(2). http://dx.doi.org/179-191. 10.1023/A:1005142606780

Gangopadhyay, P. (2002). Politics and nature of competition in oligopolistic markets. In A. Woodland (Ed.), Economic Theory and International Trade: Essays in Honour of Murray Kemp (pp. 236-243), Edward Elgar.

Gangopadhyay, P. (2004a). Strategic manipulation and information market microstructure. Australian Economic Papers, 43(1), 75-86. http://dx.doi.org/10.1111/j.1467-8454.2004.00217.x

Gangopadhyay, P. (2005). Chaotic discrimination and non-linear dynamics. American Journal of Applied Sciences, 2(1), 440-442. http://dx.doi.org/10.3844/ajassp.2005.440.442

Ghosh, P., \& Ray, D. (1996). Cooperation in community without information flows. Review of Economic Studies, 63(3), 491-519. http://dx.doi.org/10.2307/2297892

Grossman, G., \& Helpman, E. (1991). Quality ladders in the theory of growth. Review of Economic Studies, 58(1), 43-61. http://dx.doi.org/10.2307/2298044

Hopenhayn, H. (1992). Entry, exit, and firm dynamics in long run equilibrium. Econometrica, 60(5), 1127-1150. http://dx.doi.org/10.2307/2951541 
Hopenhayn, H. (2006). Knowledge, diffusion, and geography, Plenary Lecture, Society for Economic Dynamics.

Kalecki, M. (1954). Theory of Economic Dynamics: An Essay on Cyclical and Long Run Changes in Capitalist Economy. Rhinehart, New York.

Kalecki, M. (1971). Costs and Prices, Selected Essays on the Dynamics of Capitalist Economy: 1933-1970. Cambridge University Press.

Kihlstrom, R., \& Levhari, D. (1977). Quality, regulation, efficiency. Kyklos, 30(2), 214-234. http://dx.doi.org/10.1111/j.1467-6435.1977.tb02007.x

Kleiman, E., \& Ohir, T. (1966). The durability of durable goods. Review of Economic Studies, 33(2), 165-178. http://dx.doi.org/10.2307/2974440

Kopel, M. (1996). Simple and complex adjustment dynamics in Cournot duopoly models. Chaos, Solitons and Fractals, 7(12), 2031-2048. http://dx.doi.org/10.1016/S0960-0779(96)00070-7

Kranton, R. (1996). Reciprocal exchange: A self sustaining system. American Economic Review, 86(4), 830-851.

Levhari, D., \& Srinivasan, T. N. (1969). Durability of consumption goods: Competition versus monopoly. American Economic Review, 59(1), 102-107.

Liebi, T. (2002). Monitoring eco-labels: You can have too much of a good thing. Discussion Paper, University of Bern.

Mas-Colell, A., Whinston, M. D., \& Green, J. R. (1995). Microeconomic theory. Oxford Economic Press.

May, R. M. (1976). Simple mathematical models with very complicated dynamics. Nature, 261, 459-467. http://dx.doi.org/10.1038/261459a0

Murphy, K., Shleifer, A., \& Vishny, R. (1989). Industrialization and the big push. Journal of Political Economy, 97(5), 1003-1026. http://dx.doi.org/10.1086/261641

Puu, T. (1998). The Chaotic duopolists revisited. Journal of Economic Behavior and Organization, 33(3-4), 385-394. http://dx.doi.org/10.1016/S0167-2681(97)00064-4

Quah, D. (2002). 24/7 competitive innovation. mimeo, London School of Economics.

Quesada, L., \& Peyrache, E. (2004). Strategic certification. mimeo, University of Wisconson Madison.

Reynolds, P. (1987). Political Economy: A Synthesis of Kaleckian and Post Keynesian Economics. New York: St. Martin's press.

Richardson, G. P., \& Pugh, A. L. (1981). Introduction to System Dynamics Modeling with DYNAMO. Cambridge, MA: The MIT Press.

Rogerson, W. P. (1983). Reputation and product quality. Bell Journal of Economics, 14(2), 508-516. http://dx.doi.org/10.2307/3003651

Romer, P. M. (1990). Endogenous technological change. Journal of Political Economy, 98(5), S71-S102. http://dx.doi.org/10.1086/261725

Schmalensee, R. (1979). Market structure, durability, and quality: A selective survey. Economic Inquiry, 17(2), 177-96. http://dx.doi.org/10.1111/j.1465-7295.1979.tb00307.x

Schumpeter, J. A. (1942). Capitalism, socialism and democracy. New York, NY: Harper \& Row.

Shaked, A., \& Sutton, J. (1982). Relaxing price competition through product differentiation. Review of Economic Studies, 49(1), 3-14. http://dx.doi.org/10.2307/2297136

Shapiro, C. (1983). Premiums for high quality products as returns to reputations. Quarterly Journal of Economics, 98(4), 659-680. http://dx.doi.org/10.2307/1881782

Steindl, J. (1952). Maturity and stagnation in American capitalism. Blackwell: Oxford.

Swan, P. (1970). Durability of consumer goods. American Economic Review, 60(5), 884-894.

Swan, P. (1971). The durability of consumer goods and the regulation of monopoly. Bell Journal of Economics, 2, 347-357. http://dx.doi.org/10.2307/3003172

Tirole, J. (1996). A theory of collective reputations (with applications to the persistence of corruption and to firm quality). Review of Economic Studies, 63(1), 1-22. http://dx.doi.org/10.2307/2298112

Weintraub, S. A. (1959). General theory of the price level, output, income distribution and economic growth. 
Chilton: Philadelphia.

Williamson, S., \& Wright, R. (1994). Barter and monetary exchange under private information. American Economic Review, 84(1), 104-123.

Wolinsky, A. (1983). Prices as signals of product quality. Review of Economic Studies, 50(4), 647-658. http://dx.doi.org/10.2307/2297767

\section{Note}

An earlier version of this paper was presented at the Western Economic Association International (WEAI) conference, Kyoto, Japan, 24-28 March 2009. 